\title{
Age- and sex-dependent effects of early life stress on hippocampal neurogenesis
}

\author{
Manila Loi ${ }^{1}{ }^{*}$, Sylwia Koricka ${ }^{1}$, Paul J. Lucassen ${ }^{2}$ and Marian Joëls ${ }^{1}$ \\ 1 Department of Translational Neuroscience, Brain Center Rudolf Magnus, University Medical Center Utrecht, Utrecht, Netherlands \\ ${ }^{2}$ Swammerdam Institute for Life Sciences - Center for Neuroscience, University of Amsterdam, Amsterdam, Netherlands
}

\section{Edited by:}

Nikolaos P. Daskalakis, Icahn School of Medicine at Mount Sinai, USA

Reviewed by:

Thomas Dickmeis, Karlsruhe Institute of Technology, Germany

Gábor B. Makara, Hungarian Academy of Sciences, Hungary

${ }^{*}$ Correspondence:

Manila Loi, Department of

Translational Neuroscience, Brain

Center Rudolf Magnus, University

Medical Center Utrecht,

Universiteitsweg 100, 3584 CG

Utrecht, Netherlands

e-mail:m.loi@umcutrecht.nl
Early life stress is a well-documented risk factor for the development of psychopathology in genetically predisposed individuals. As it is hard to study how early life stress impacts human brain structure and function, various animal models have been developed to address this issue. The models discussed here reveal that perinatal stress in rodents exerts lasting effects on the stress system as well as on the structure and function of the brain. One of the structural parameters strongly affected by perinatal stress is adult hippocampal neurogenesis. Based on compiled literature data, we report that postnatal stress slightly enhances neurogenesis until the onset of puberty in male rats; when animals reach adulthood, neurogenesis is reduced as a consequence of perinatal stress. By contrast, female rats show a prominent reduction in neurogenesis prior to the onset of puberty, but this effect subsides when animals reach young adulthood. We further present preliminary data that transient treatment with a glucocorticoid receptor antagonist can normalize cell proliferation in maternally deprived female rats, while the compound had no effect in non-deprived rats. Taken together, the data show that neurogenesis is affected by early life stress in an age- and sex-dependent manner and that normalization may be possible during critical stages of brain development.

Keywords: maternal deprivation, maternal separation, stress, rat, dentate gyrus, adult neurogenesis, proliferation, hippocampus

\section{EARLY LIFE STRESS AND BRAIN DEVELOPMENT}

Early life represents a critical phase in brain development as many regions are not fully formed at birth or undergo extended postnatal maturation. The dentate gyrus (DG), part of the hippocampal formation, is an extreme case where the majority of neurons are generated after birth (1). The continued formation of new neurons after birth, known as adult neurogenesis, is restricted to a limited number of brain areas: in addition to the DG, neurogenesis occurs in the subventricular zone (SVZ) and in the olfactory bulb (2). Even in other parts of the brain, growth is not completed at birth. For instance, the prefrontal cortex (PFC) continues to develop well into adulthood (3). Cortical thickness in humans reaches a maximum around age 35 (4). In addition to the progressive growth until adulthood, new connections continue to be formed, too. The intricate formation and pruning of essential contacts eventually lead to an effective connectome and functional network (5).

It is therefore not surprising that potential or actual perturbations in the individual's environment and "homeostasis" - subjectively experienced as "stress" - particularly when these take place during the critical phase of early development, can have important lasting consequences for brain structure and function later in life (Figure 1). In interaction with the genetic profile, early environmental influences "shape" brain maturation as well as the way in which an individual deals with environmental challenges throughout the rest of life. In humans, brain structure and function as well as the ability to cope with stress together determine the vulnerability to psychopathology. Retrospective case-control studies for various psychiatric illnesses, including post-traumatic stress disorder (PTSD) (6), depression (7), schizophrenia (8), and also borderline syndrome (9), have consistently shown that early life adversity is a significant risk factor. The risk increases when early life adversity is severe, prolonged, repeated, and/or characterized by a lack of control over the situation (10). Prospective studies, though more rare, confirm this view [see e.g., Ref. (11-13)].

The sequential steps through which early life adversity changes brain structure and function in a lasting manner, and hence the later risk for psychopathology, is hard to investigate in human subjects, given the long duration of brain maturation, the restrictions in obtaining detailed information about signal transduction in the brain and the lack of control over both genetic and environmental factors. Therefore, research has resorted to animal models, which have fewer of these drawbacks.

In rodents, many models for early life adversity have been developed $(14,15)$. Some intervene with the prenatal environment, e.g., by stressing the pregnant female (16-19) or by exposing her to compounds acting on stress hormone receptors, e.g., dexamethasone (20). The majority of models, though, focus on the postnatal environment. Since the care provided by the dam represents a strong environmental influence during the first postnatal weeks, many models have specifically concentrated on (disturbed) mother-pup interactions. One model, developed largely by Michael Meaney and coworkers, makes use of natural variations in maternal care provided by the dams (21). Their licking and grooming behavior shows a classic normal distribution, 


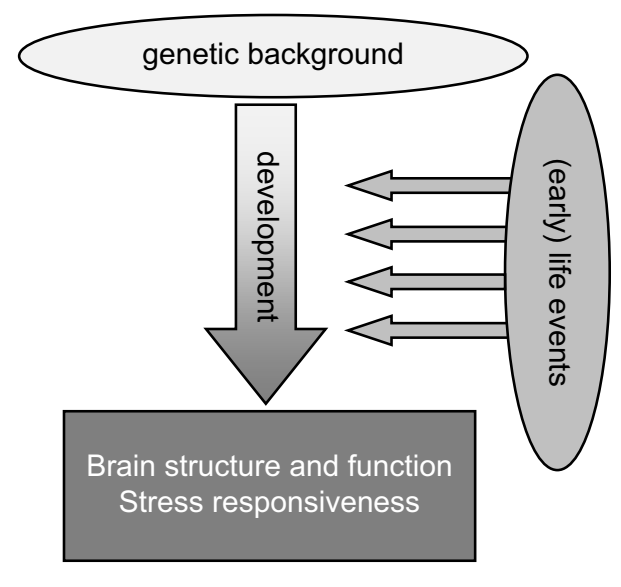

FIGURE 1 | General scheme highlighting that life events, especially when experienced during the early developmental stage, may strongly impact the development of the brain, especially in genetically

susceptible individuals. These gene-environment interactions during development will strongly contribute to the overall brain structure and function as well as stress responsiveness in adulthood.

with the majority of the mothers providing moderate amounts of care (22). However, some mothers show extremely high or low amounts of licking-grooming behavior ( $>1$ standard deviation above or below the mean respectively). Their offspring can be examined in adulthood and even into the next generation to study consequences of maternal care (22). Notably, through crossfostering, the influence of maternal care can be dissociated from the contributions of the genetic background (23).

Many other models actively intervene with the mother-pup interaction, e.g., by limiting the bedding and nesting material in the cage, which induces fragmented care in the dam (24). This, in turn, has lasting consequences for brain development and behavior in the offspring. Separation of the pups from the mother has also been applied in various models. This can range from brief, daily separations to more extreme conditions where the dam and her offspring are separated for up to $24 \mathrm{~h}$. Brief separations, e.g., $15 \mathrm{~min}$ handling of the pups during the first postnatal weeks, actually results in an overall enhancement of maternal care, because the mother bestows more care on her pups upon their return to the cage; this has been used as a model for environmental enrichment (25). More prolonged separations, e.g., for $3 \mathrm{~h}$ daily between postnatal days (PND) 2 and 14 or deprivation of the mother for $24 \mathrm{~h}$ at PND 3 or 9, can be considered models for impoverished and poor care or even neglect (26).

Studies using these models have shown that many aspects of brain structure and function are strongly affected by early life adversity, some of which can be normalized by environmental enrichment $(27,28)$. One set of data pertains to the development of the stress response itself. Stress rapidly activates the autonomic nervous system, eventually causing the release of (nor)adrenaline from the adrenal medulla. Slightly later, the hypothalamic-pituitary-adrenal (HPA) axis is activated, which leads to release of corticosteroid hormones (corticosterone in rodents and cortisol in humans) from the adrenal cortex into the circulation; this response is terminated $1-2 \mathrm{~h}$ later by negative feedback actions of corticosteroids at the level of the pituitary gland, the hypothalamus, and extra-hypothalamic regions $(29,30)$. Thus, after stress, the brain is exposed to successive waves of noradrenaline and (slightly later) corticosteroid hormones, which have their own and combined roles in mediating effects of stress on the brain, that normalize some hours later (31). In the brain, corticosteroids bind to discretely localized intracellular receptors, most notably the glucocorticoid receptor (GR) that is enriched in hippocampal CA1 and dentate granule cells (29). Corticosteroids also bind to another receptor, the mineralocorticoid receptor, but the affinity for this receptor is very high, so that it is substantially bound to corticosteroids already under conditions of rest $(29,32)$. Early life adversity was found to reduce the number of hippocampal GRs and impair the negative feedback, causing prolonged exposure of the brain to corticosteroids in the aftermath of stress (33).

In addition to effects on stress responsiveness, also brain structure and function are affected by the early life environment (26). Many studies have shown that, e.g., the complexity of dendritic trees, the number of synaptic contacts and growth factor levels depend on early life history, although the direction of these effects can be region dependent (34). Similarly, the extent of neurogenesis in adolescence and adulthood is affected by circumstances experienced earlier in life (7). In this paper, we will highlight the effects of the early life environment on hippocampal neurogenesis (see below), focusing on stress experienced just prior to, or during, the first 2 postnatal weeks.

Not only structural plasticity but also functional plasticity has been the subject of study. For instance, hippocampal long-term potentiation, i.e., the prolonged strengthening of synaptic contacts, which is thought to underlie memory formation (35), is generally impaired in adult rats that experienced fragmented or low levels of maternal care, or were separated from the mother during the first postnatal weeks $(36,37)$. These structural and functional changes contribute to behavioral changes. For instance, contextual hippocampus-dependent memory is impaired in adult rats that experienced reduced amounts of maternal care, be it due to natural variations $(27,37,38)$ or imposed by separation $(39$, 40). However, other cognitive domains - e.g., decision making or reward processes that depend on an optimal function of the PFC - are also disturbed in adult rodents with a history of early life adversity $(41,42)$.

The overall adaptive value of these long-term changes in stress responsiveness, brain structure and function after early life adversity can be best appreciated when studying individuals under various circumstances later in life. For instance, long-term potentiation and hippocampus-dependent learning are impaired under non-stressful experimental conditions in adult offspring from low licking-grooming mothers, or in animals with a history of $24 \mathrm{~h}$ of $\mathrm{MD}$ at PND $3(37,38,40,43)$. In contrast, when these animals are tested under conditions of elevated corticosterone levels, long-term potentiation and hippocampus-dependent learning are actually improved $(37,38,40)$. This suggests that the early life environment may affect brain development in such a way that the network can optimally perform under comparable, i.e., matching, conditions later in life. Inadequate responses may arise when there is a mismatch between early life, and the predictions, or "settings" 
based on that environment on the one hand, and the actual, later life conditions the individual experiences at an adult age on the other hand (44-46).

\section{NEUROGENESIS}

Adult neurogenesis refers to the formation of new, functional neurons that originate from stem cells present in the adult brain. This form of structural plasticity occurs in at least two brain regions; the SVZ of the lateral ventricles, from where cells migrate through the rostro-migratory stream toward the olfactory bulb, and in the subgranular zone (SGZ) of the hippocampal DG. Adult neurogenesis is strongly affected by the early life environment $(7,47,48)$. Whereas in the SVZ, the newborn cells participate in olfactory learning, and newborn cells in the DG have been implicated in specific aspects of spatial memory formation and cognition such as pattern separation (49).

During the dynamic process of neurogenesis, stem cells go through several, distinct stages of development (50). Following an initial phase of proliferation during which the initial stem cell pool mainly undergoes expansion, a selection process occurs after approximately 1 week during which around $50 \%$ of the newly generated cells die through apoptosis. The surviving cells use radial glia cells as a scaffold to migrate into the granule cell layer, where they eventually differentiate into a mature neuronal phenotype. The proliferation phase is often studied using immunocytochemical markers like Ki-67 or proliferating cell nuclear antigen, while the differentiation phase is usually investigated with doublecortin (DCX), a microtubule-associated protein expressed in young migratory neurons (51). The spatio-temporal expression pattern of DCX largely coincides with the process of adult neurogenesis in the rat hippocampus. Cell survival and cell fate can be studied several weeks after (intra-peritoneal) pulse labeling with bromo-deoxy-uridine ( $\mathrm{BrdU})$, a compound that is incorporated into the DNA of dividing cells. The fate and progeny of BrdU-incorporating cells can then later be monitored using double-immunofluorescent labeling with markers for mature neuronal or glial cells. With viral vectors, which label only dividing cells, it has been shown that most adult-born cells, 3-4 weeks after their birth, express adult neuronal markers and are functionally incorporated within the existing DG network (52).

The process of neurogenesis is regulated by several environmental factors including enriched environmental housing or physical exercise, both stimulating the survival of the newborn neurons (53). By contrast, aging and exposure to acute or chronic stress strongly suppress one or more phases of the neurogenic process (54).

Elevated stress hormone levels or an activated HPA-axis is commonly observed in depressed patients. Recent studies have further suggested that also impairments in structural plasticity, including neurogenesis, may be involved in the pathophysiology of depression and in the hippocampal volume reduction in this disorder (55). This "neurogenic theory" of depression postulates that a suppressed rate of cyto- or neurogenesis contributes to the (vulnerability for) depression (56-58), and is supported by the findings that: (1) stress inhibits neurogenesis in animals and is a risk factor for depression; (2) depressed patients often display hippocampal volume reductions parallel to cognitive deficits and HPA activation; (3) most antidepressant drugs do not exert their therapeutic effect until after 3-4 weeks of administration, a time-to-effect that parallels the maturation period of adult newborn neurons; (4) many antidepressants increase or normalize reductions in neurogenesis, particularly in young animals; and (5) disruption of neurogenesis blocks the behavioral response to antidepressant drugs $(59,60)$. However, this theory is not always supported and still under debate $(58,61,62)$.

While stress-induced reductions of neurogenesis occurring during adulthood are generally reversible, e.g., after appropriate recovery periods or antidepressant drug treatment, the changes induced by early life stress are generally longer lasting and the consequences often persist throughout life (see further below). One reason for this difference could be that stress occurring during early life interferes with the development of the DG, which is largely postnatal in rodents. However, it remains poorly understood why such deficits are so long-lasting and whether they can be prevented or reversed at all.

\section{AGE- AND SEX-DEPENDENT EFFECTS OF PERINATAL STRESS}

Adult neurogenesis is sensitive to the early life environment. As summarized in Table 1, perinatal stress in male rats was generally found to suppress neurogenesis $(17,63)$. The effects appear to be region-specific: for instance, prenatal stress impaired neurogenesis in the DG but not in the olfactory bulb (64).

The overall effect of stress on neurogenesis also depends on the developmental stage during which the organism experiences stress. Thus, in utero exposure to stress or to a variety of pharmacological agents almost invariably reduces neurogenesis in adulthood (Table 1). Postnatal exposure to stress yields more variable results, though suppression of neurogenesis prevails here also.

More importantly, the consequences of early life environment depend on the moment at which neurogenesis is determined. When tested in adulthood or middle-age, cell proliferation and neurogenesis were usually found to be decreased (Table 1, Figure 2). Yet, at earlier stages, e.g., at PND $21(70,75)$, neurogenesis in males was actually found to be enhanced by early life stress (Figure 3), as was BDNF expression and performance in a stressful version of the Morris water maze (75). Apparently, early life adversity can transiently improve dentate functionality, possibly to allow the organism to survive in the adverse conditions. However in the long run, early life adversity seems to program structural plasticity such that it may become a disadvantage, most notably under low to moderately stressful conditions. Overall, this gives rise to a significant negative correlation between the number of proliferating (Ki-67 or BrdU-positive cells; $r^{2}=-0.464, p=0.05$; Pearson test) or DCX-positive $\left(r^{2}=-0.623, p=0.017\right)$ neurons and age in male rodents.

Strikingly different effects of early life stress on neurogenesis are seen in female rats (Figure 2). Whereas neurogenesis is enhanced at PND 21 in male rats exposed to $24 \mathrm{~h}$ of maternal deprivation at PND 3, a strong suppression was reported in females (Figure 3). However, in females the consequence of early life adversity for the number of DCX-positive cells subsides with age, resulting in an overall positive correlation between the number of DCX-positive cells and age $\left(r^{2}=0.737, p=0.037\right)$. By PND 29 , the effects of maternal deprivation on neurogenesis are far less 


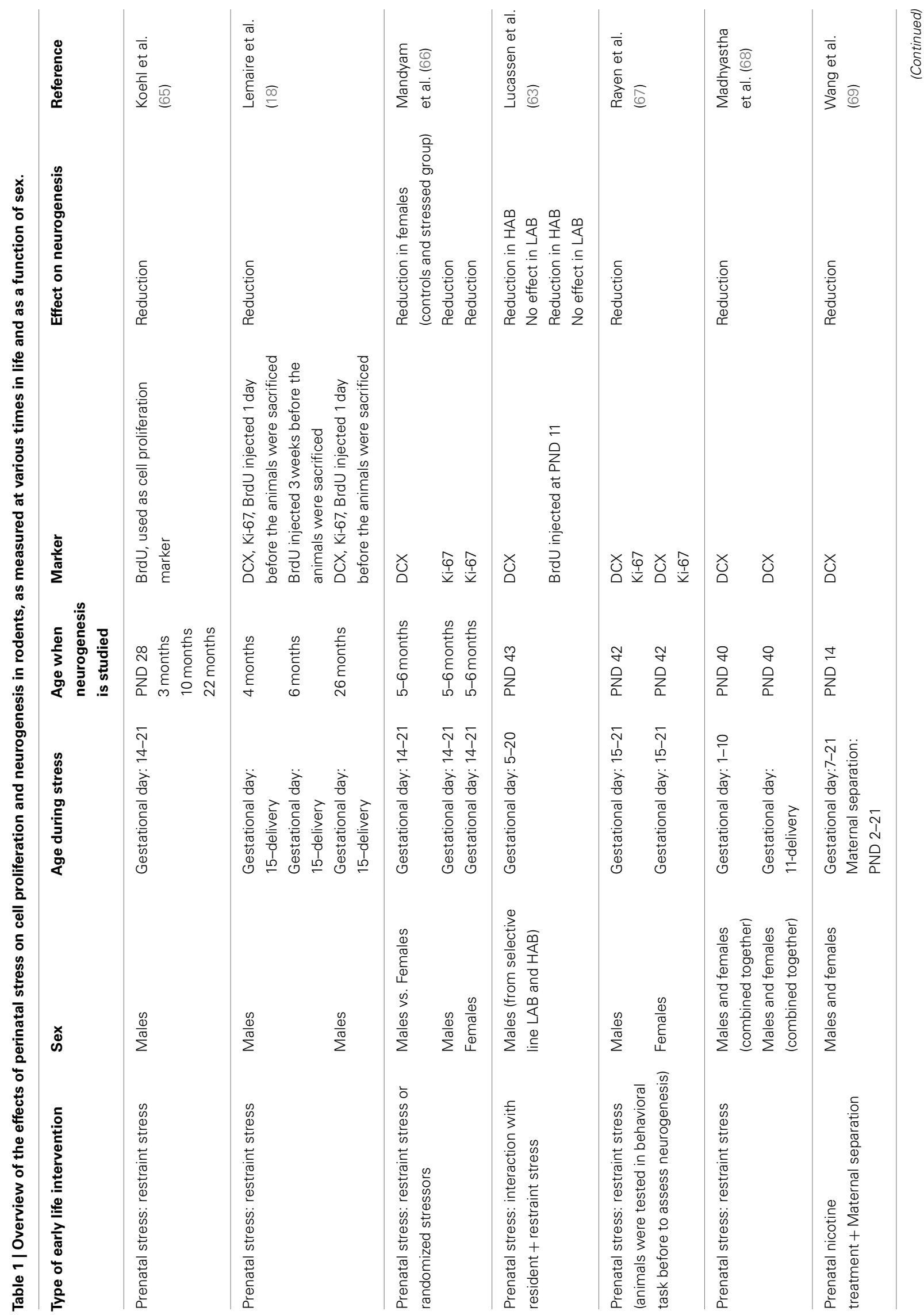




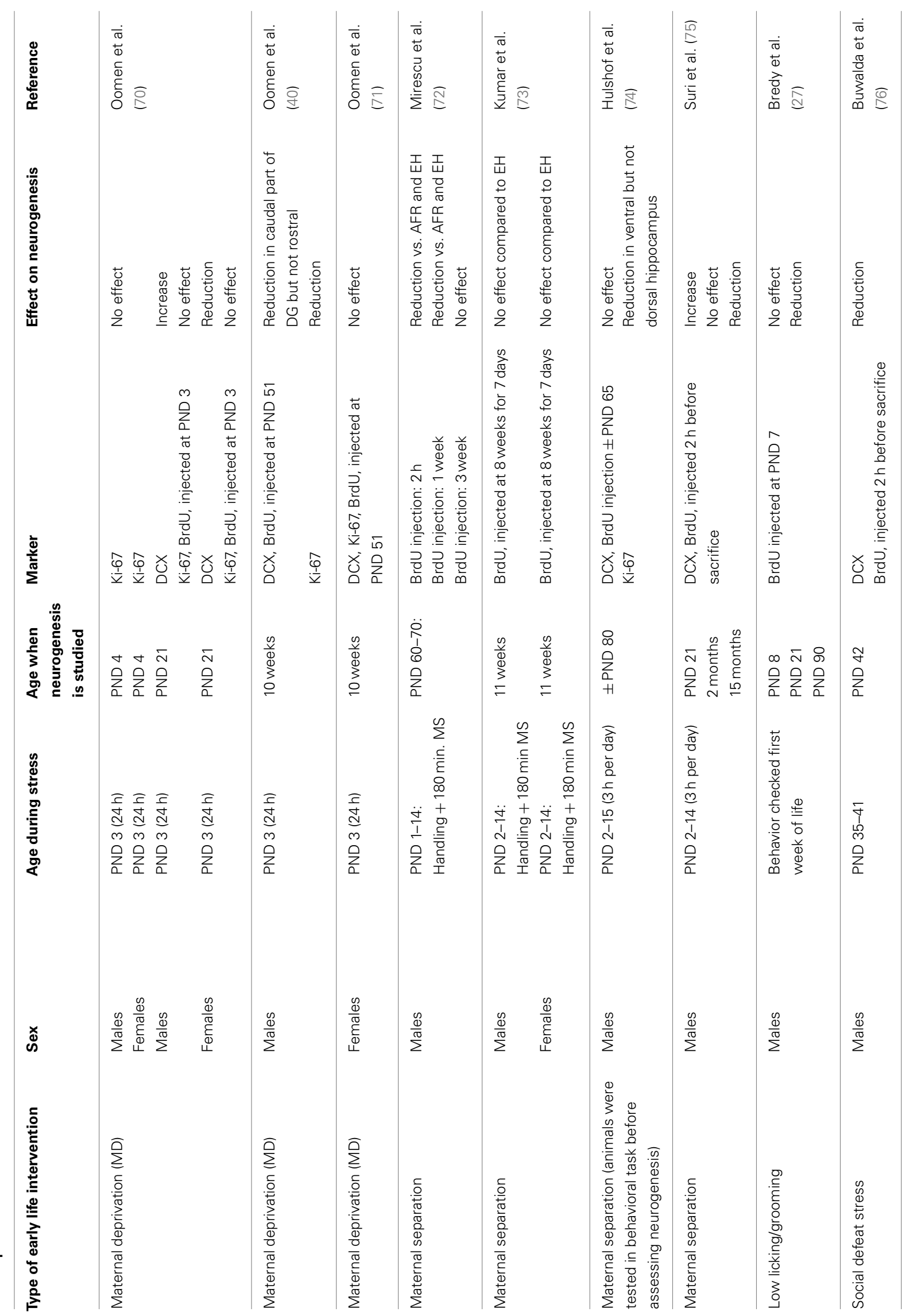


A
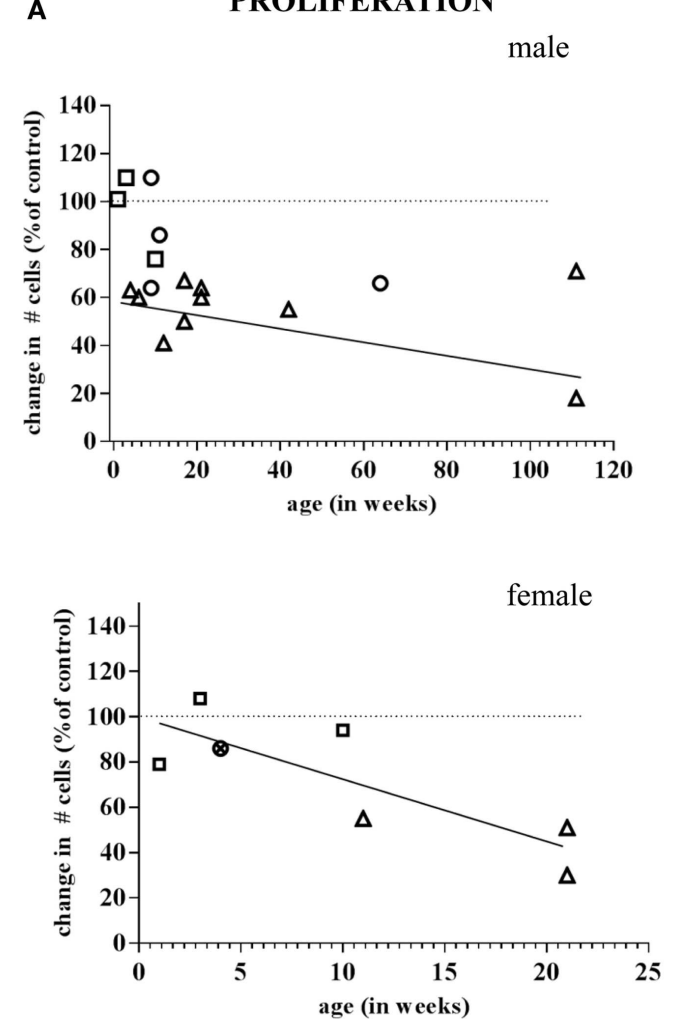

B

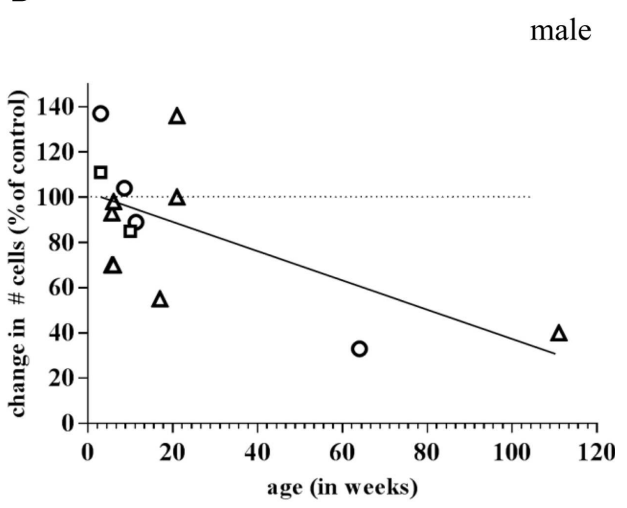

NEUROGENESIS

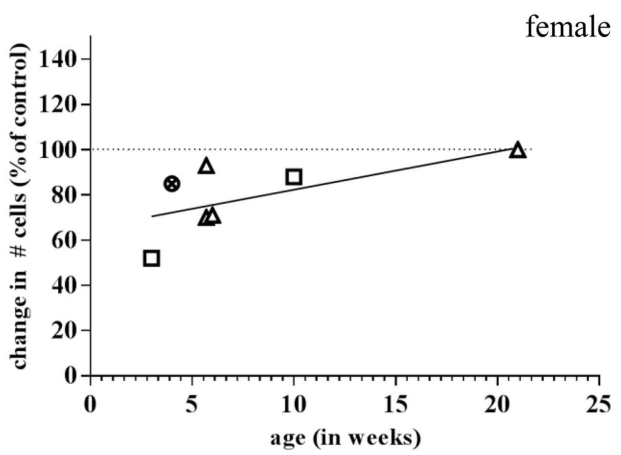

- maternal separation

a maternal deprivation

$\Delta$ prenatal stress

- value from our data

FIGURE 2 | Meta-analysis of age- and sex-dependent effects of early life adversity on neurogenesis. The graphs show the percentage change in number of Ki-67 and Doublecortin (DCX)-positive cells after perinatal stress ( $y$-axis; $100 \%$ is control), as a function of the age at which the change in neurogenesis was determined ( $x$-axis, in weeks). (A) Both in males (top) and females (bottom), the change in number of Ki-67 positive cells due to prenatal (triangle), maternal separation (diamond) or maternal deprivation (square) was negatively correlated to the age at which the effect was determined.

(B) In male rodents (top), the number of DCX-positive cells was found to be enhanced by perinatal stress when examined at a very young age. When

studied at time-points $>2$ months of age, generally a decrease in the number of DCX-positive cells was observed. Overall, this resulted in a negative correlation between the effect of early life stress on neurogenesis and the age at which these effects were apparent. In female rats (bottom), we observed a correlation in the opposite direction. The data points are based on the references summarized in Table 1. The one data-point depicted by the filled symbol in the graphs of the females represents the percentage change found in the pilot study described in Figure 4 (not incorporated in Table 1). The striped horizontal line in the graphs indicates the control condition (i.e., the non-stressed groups mentioned in the same publications) against which the number of cells in the stress groups was expressed. The drawn line indicates the best fit for the linear correlation. prominent than seen at PND 21 [Figure 2 (filled symbol) and Figure 4]. However, the correlation between the change in number of proliferating neurons due to early life adversity and the age at which the effects were determined was comparable between males and females $\left(r^{2}=-0.816, p=0.025\right)$. This could suggest that in female proliferation of non-neuronal (e.g., glial) cells in adulthood is very sensitive to early life adversity or, vice versa, that proliferation of non-neuronal cells is stimulated around weaning, compensating for the loss in young neurons due to perinatal stress.

\section{ESSENTIAL MEDIATORS}

The molecular pathways through which early life stress can lastingly change stress responsiveness, brain structure and functional performance are only starting to be explored. There is now evidence that epigenetic programing is involved $(48,78)$, possibly targeting diverse mediators such as NFKB (79), SGK1 (80) or critical steps in the glutamate signaling pathway (81). The GR seems to be a particularly critical element in the cascade leading to lasting changes in brain structure and function. For instance, exon I-7 of the GR promoter is transiently methylated during early development, and again subject to demethylation after PND 6 (82). This demethylation did not occur in the offspring from low licking and grooming mothers. Temporary treatment with a histone deacetylase inhibitor, a compound that prevents the removal of acetyl groups from histones, thus enabling transcription, could fully prevent the development of the phenotype-characterized by reduced hippocampal GR 


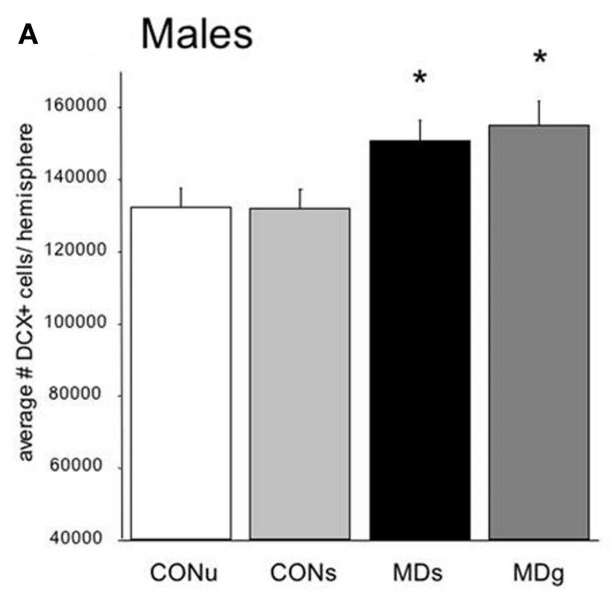

FIGURE 3 | Sex-dependent effects of maternal deprivation on neurogenesis. (A) The number of Doublecortin (DCX)-positive neurons in the entire dentate gyrus from 21-days-old male rats, which underwent $M D$ for $24 \mathrm{~h}$ at postnatal day (PND) 3, was significantly ( ${ }^{*} p<0.05 ; n=7$ animals) enhanced compared to the non-deprived controls (CON). Half of the animals received glucose $(\mathrm{g})$ on day 3 , to compensate for the loss in

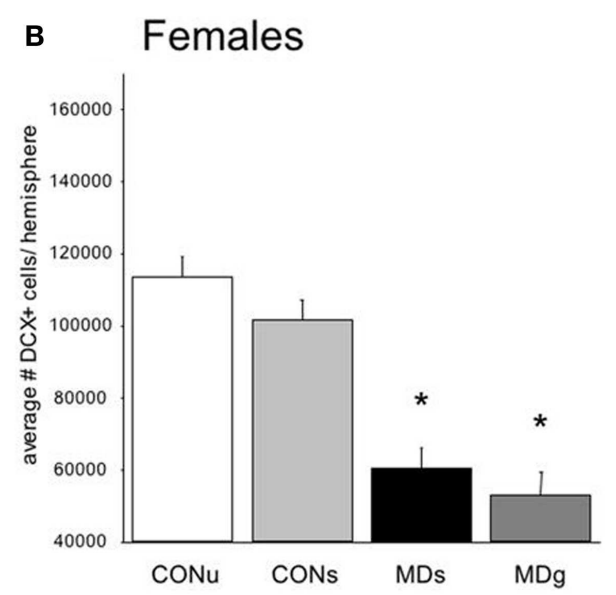

nutrients, while the remaining animals received saline (s). There was no effect of sucrose compared to saline treatment. (B) The opposite effect was observed in the female littermates: i.e., the number of DCX-positive neurons on PND 21 was significantly reduced in maternally deprived compared to non-deprived rats, regardless of sucrose/saline treatment $(n=7)$. From Ref. (70). expression and an impaired negative feedback of the stress induced stress response - in adult offspring of low licking-grooming mothers $(82,83)$. This suggests that the reduction of GR expression in the offspring of low licking-grooming mothers - and hence corticosteroid over-exposure, particularly after stress - may at least partly be responsible for the structural and functional alterations reported along the lifespan and are likely mediated by epigenetic changes.

If corticosteroid over-exposure is indeed an essential step in the cascade, one would expect to see beneficial effects of treatment with pharmacological agents that block the GR, i.e., the receptor most prominently activated after stress. To test this, we performed a pilot study in which female rats, exposed to maternal deprivation at PND 3, were treated during a critical developmental window with the GR antagonist mifepristone. We selected the period of PND 26-28 for treatment with mifepristone, as earlier studies have shown that interventions at this stage of development have significant consequences for the development of the brain and the response to stress later in life (84). Moreover, we had demonstrated before that even a brief treatment with mifepristone is very powerful in normalizing the effects of chronic stress in adult rats (77).

As shown in Figure 4, the number of Ki67-positive cells was significantly higher in the hilus (but not in the DG as a whole, data not shown) in MD rats treated with mifepristone compared to those treated with vehicle, whereas the drug did not affect the number of Ki67-positive cells in non-deprived rats. Similarly, mifepristone treatment tended to cause higher levels of DCX-positive cells in the dentate supra-pyramidal blade of MD rats compared to vehicle treated MD controls, although this did not reach significance $(p=0.08)$; mifepristone did not affect the number of DCX-positive cells in non-deprived rats. It should be noted that the effects were modest, possibly due to the age (PND 29) at which the effects of maternal deprivation were determined. More definite conclusions about the potential of mifepristone to reverse effects of maternal deprivation on cell proliferation and neurogenesis require extension of the current pilot experiment to analysis at an earlier time-point - when effects on neurogenesis are more clearly discernable in females, e.g., at PND 21, combined with mifepristone treatment at an earlier time-point, too. Nevertheless, the results are generally in line with earlier findings that brief treatment with the GR-antagonist mifepristone can quickly normalize effects of stress on neurogenesis (77).

\section{CONCLUDING REMARKS}

Rodent studies over the past decades have shown that neurogenesis appears to be very sensitive to stress, particularly when stress occurs during the perinatal period. As has become evident from the current overview, these effects of perinatal stress are clearly agedependent: the consequences seem to change in nature depending on the interval between early life adversity and the time of analysis of the effects on neurogenesis. Interestingly, the effects of perinatal stress on neurogenesis are also sex-dependent. Male rats show a brief period in adolescence during which neurogenesis, BDNF expression, and spatial learning are actually improved, possibly allowing the individual to temporarily compensate for the effects of early life adversity. Female rats do not show such a period of improved performance but rather show a very strong suppression of neurogenesis during the pre-pubertal period, which then subsides with age. The consequences of this period of suppressed neurogenesis in females, though, may be long-lasting. For instance, female rats exposed to $24 \mathrm{~h}$ of maternal deprivation at PND 3 exhibited a lower total number of mature granule cells in adulthood (71), potentially limiting the number of synaptic contacts that can be established in this region. Preliminary studies indicate that intervention at the pre-pubertal stage is possible, e.g., by 
A

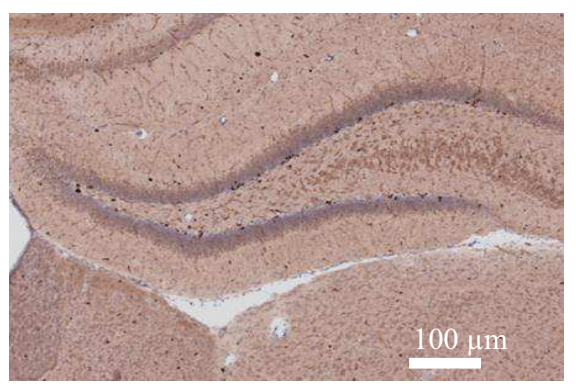

Females

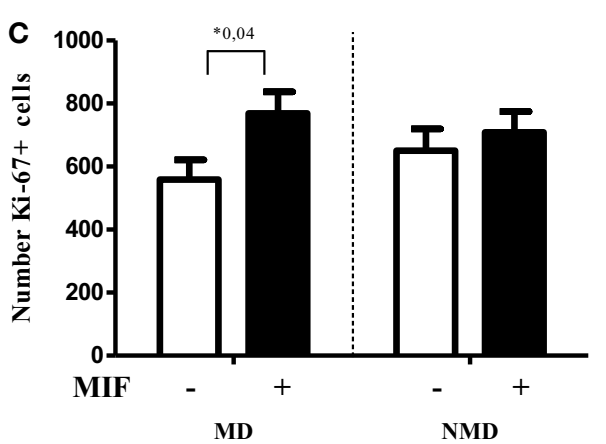

FIGURE 4 | Brief treatment with the GR antagonist mifepristone protects female rats against the effects of early life stress. Rats were deprived from their mother for $24 \mathrm{~h}$ at PND 3, following the procedure as described in Oomen et al. (70). After weaning at PND 21, they were group-housed with same-sex same-littermates. On PND 26-28 each rat received mifepristone twice daily (5 mg of RU-38486 (Sigma) per $100 \mathrm{~g}$ of body weight, dissolved first in $15 \mu \mathrm{l}$ ethanol and then in $1.5 \mathrm{ml}$ coffee cream (Campina, Woerden, The Netherlands) and administered by oral gavage (77). One day later, at PND 29, female rats were transcardially perfused with saline, followed by $4 \%$ paraformaldehyde in phosphate buffer $(0.1 \mathrm{M} ; \mathrm{pH} 7.4)$. Tissue handling and staining for DCX and the proliferation marker Ki67 was conducted as described in Oomen et al. (70). (A) Typical example of Ki-67 staining in the DG of a control female rat. (B) Typical example of DCX staining in the DG of a control female rat. (C) Cell proliferation at PND 29, as determined with Ki-67 staining, was significantly increased in the hilus of MD female rats treated with mifepristone (MIF) on PND 26-28, compared to those treated with

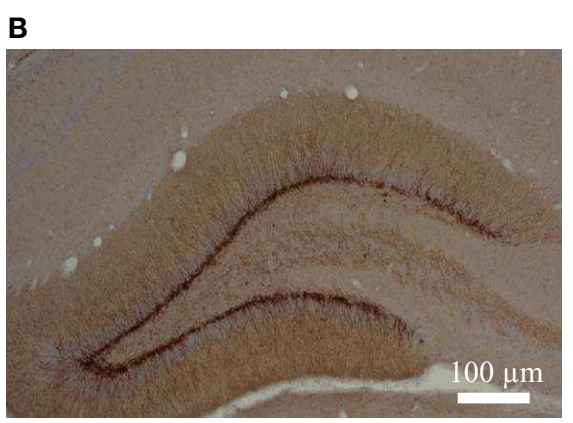

Females

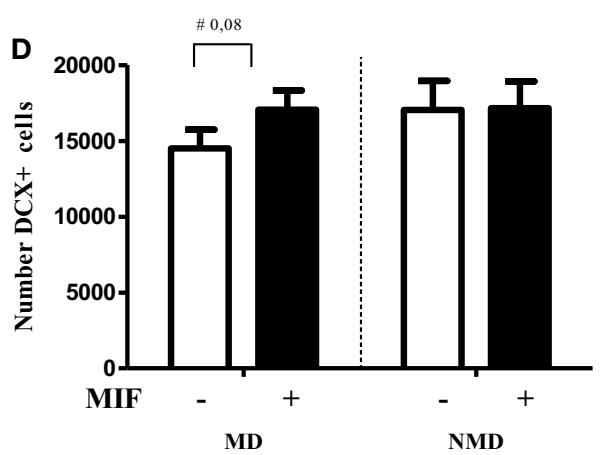

vehicle. MIF had no effect in non-deprived (NMD) rats. No significant differences between the experimental groups were seen in the dentate as a whole (data not shown). For each animal, we counted the number of Ki67-positive cells in every 10th section and from this the total number of Ki67-positive cells per hemisphere was inferred. All bars represent the mean + SEM per group ( $n=7-9$ animals per group). (D) In the supra-pyramidal blade, a trend $(p=0.08)$ toward a significant increase in the number of DCX-positive cells in MD female rats treated with MIF vs. those treated with vehicle was observed. Mifepristone did not alter neurogenesis at all in NMD rats. Though the percentage change in the infrapyramidal blade and the dentate gyrus as a whole showed a comparable pattern, these differences were not significant ( $p>0.1$, data not shown). For each animal, we counted every 10 th section sampled in an unbiased stereological manner, yielding up to a total of nine sections per animal. We then expressed the average number of DCX-positive cells per section per animal. All bars represent the mean + SEM per group ( $n=11-12$ animals per group). blocking GRs for a limited number of days. Clearly, these studies on successful intervention strategies require more extensive followup, to precisely determine the effectiveness of various treatment regimes.

One can speculate about the implications of findings in animal models of perinatal stress for human brain development and the vulnerability to psychopathology. In general, the study of actual neurogenesis in the human brain is difficult and, although its existence has been convincingly demonstrated, it has largely relied on immunocytochemical approaches using proliferation markers in postmortem tissues. Although neurogenesis in adult and aged individuals is generally rare, much larger levels are present at earlier ages $(85,86)$. It is currently thought that antidepressant treatment may target the neurogenetic process and in fact requires the newborn cells for their antidepressant action to be exerted (87), although this is mostly based on studies in young animal models (60). The finding that especially female rats showed suppressed neurogenesis during a critical developmental stage in response to early life adversity is of interest, given the higher prevalence of many psychiatric illnesses in the female population. In humans, careful monitoring of genetically predisposed females with a history of early life adversity during their development, including possibilities for early intervention, may therefore be one approach to mitigate the development of psychopathology.

\section{ACKNOWLEDGMENTS}

Manila Loi was financially supported by Corcept Therapeutics. Paul J. Lucassen is supported by ISAO, Alzheimer Nederland and the HersenStichting Nederland. We thank Mr. G. Meerhoff (SILS, UvA) for histotechnical assistance and Hazel Hunt and Joe Belanoff for helpful comments. 


\section{REFERENCES}

1. Kohman RA, Rhodes JS. Neurogenesis, inflammation and behavior. Brain Behav Immun (2013) 27:22-32. doi:10.1016/j.bbi.2012.09.003

2. Kempermann G. New neurons for 'survival of the fittest'. Nat Rev Neurosci (2012) 13:727-36. doi:10.1038/nrn3319

3. Kolb B, Mychasiuk R, Muhammad A, Li Y, Frost DO, Gibb R. Experience and the developing prefrontal cortex. Proc Natl Acad Sci U S A (2012) 109(Suppl 2):17186-93. doi:10.1073/pnas.1121251109

4. Brans RG, Kahn RS, Schnack HG, van Baal GC, Posthuma D, van Haren NE, et al. Brain plasticity and intellectual ability are influenced by shared genes. J Neurosci (2010) 30:5519-24. doi:10.1523/JNEUROSCI.5841-09.2010

5. Sporns O. The human connectome: a complex network. Ann NYAcad Sci (2011) 1224:109-25. doi:10.1111/j.1749-6632.2010.05888.x

6. Raabe FJ, Spengler D. Epigenetic risk factors in PTSD and depression. Front Psychiatry (2013) 4:80. doi:10.3389/fpsyt.2013.00080

7. Korosi A, Naninck EF, Oomen CA, Schouten M, Krugers H, Fitzsimons C, et al. Early-life stress mediated modulation of adult neurogenesis and behavior. Behav Brain Res (2012) 227:400-9. doi:10.1016/j.bbr.2011.07.037

8. Jiang Z, Cowell RM, Nakazawa K. Convergence of genetic and environmental factors on parvalbumin-positive interneurons in schizophrenia. Front Behav Neurosci (2013) 7:116. doi:10.3389/fnbeh.2013.00116

9. Schmahl CG, Vermetten E, Elzinga BM, Douglas BJ. Magnetic resonance imaging of hippocampal and amygdala volume in women with childhood abuse and borderline personality disorder. Psychiatry Res (2003) 122:193-8. doi:10.1016/S0925-4927(03)00023-4

10. Heim C, Nemeroff CB. The impact of early adverse experiences on brain systems involved in the pathophysiology of anxiety and affective disorders. Biol Psychiatry (1999) 46:1509-22. doi:10.1016/S0006-3223(99)00224-3

11. Zimmermann P, Brückl T, Nocon A, Pfister H, Binder EB, Uhr M, et al. Interaction of FKBP5 gene variants and adverse life events in predicting depression onset: results from a 10-year prospective community study. Am J Psychiatry (2011) 168:1107-16. doi:10.1176/appi.ajp.2011.10111577

12. Belsky DW, Caspi A, Arseneault L, Bleidorn W, Fonagy P, Goodman M, et al. Etiological features of borderline personality related characteristics in a birth cohort of 12-year-old children. Dev Psychopathol (2012) 24:251-65. doi:10.1017/S0954579411000812

13. Breslau N, Koenen KC, Luo Z, Agnew-Blais J, Swanson S, Houts RM, et al. Childhood maltreatment, juvenile disorders and adult post-traumatic stress disorder: a prospective investigation. Psychol Med (2013) 29:1-9. doi:10.1017/ S0033291713002651

14. Pryce CR, Ruedi-Bettschen D, Dettling AC, Weston A, Russig H, Ferger B, et al. Long-term effects of early-life environmental manipulations in rodents and primates: potential animal models in depression research. Neurosci Biobehav Rev (2005) 29:649-74. doi:10.1016/j.neubiorev.2005.03.011

15. Schmidt MV, Wang XD, Meijer OC. Early life stress paradigms in rodents: potential animal models of depression? Psychopharmacology (Berl) (2011) 214:131-40. doi:10.1007/s00213-010-2096-0

16. Koenig JI, Walker CD, Romeo RD, Lupien SJ. Effects of stress across the lifespan. Stress (2011) 14:475-80. doi:10.3109/10253890.2011.604879

17. Lemaire V, Koehl M, Le MM, Abrous DN. Prenatal stress produces learning deficits associated with an inhibition of neurogenesis in the hippocampus. Proc Natl Acad Sci U S A (2000) 97:11032-7. doi:10.1073/pnas.97.20.11032

18. Lemaire V, Lamarque S, Le MM, Piazza PV, Abrous DN. Postnatal stimulation of the pups counteracts prenatal stress-induced deficits in hippocampal neurogenesis. Biol Psychiatry (2006) 59:786-92. doi:10.1016/j.biopsych.2005. 11.009

19. van den Hove DL, Leibold NK, Strackx E, Martinez-Claros M, Lesch KP, Steinbusch HW, et al. Prenatal stress and subsequent exposure to chronic mild stress in rats; interdependent effects on emotional behavior and the serotonergic system. Eur Neuropsychopharmacol (2013) (in press). doi:10.1016/j.euroneuro. 2013.09.006

20. Welberg LA, Seckl JR. Prenatal stress, glucocorticoids and the programming of the brain. J Neuroendocrinol (2001) 13:113-28. doi:10.1111/j.1365-2826.2001. 00601.x

21. Zhang TY, Labonte B, Wen XL, Turecki G, Meaney MJ. Epigenetic mechanisms for the early environmental regulation of hippocampal glucocorticoid receptor gene expression in rodents and humans. Neuropsychopharmacology (2013) 38:111-23. doi:10.1038/npp.2012.149
22. Champagne FA. Maternal imprints and the origins of variation. Horm Behav (2011) 60:4-11. doi:10.1016/j.yhbeh.2011.02.016

23. Holmes A, Le Guisquet AM, Vogel E, Millstein RA, Leman S, Belzung C. Early life genetic, epigenetic and environmental factors shaping emotionality in rodents. Neurosci Biobehav Rev (2005) 29:1335-46. doi:10.1016/j.neubiorev.2005.04.012

24. Baram TZ, Davis EP, Obenaus A, Sandman CA, Small SL, Solodkin A, et al. Fragmentation and unpredictability of early-life experience in mental disorders. Am J Psychiatry (2012) 169:907-15. doi:10.1176/appi.ajp.2012.11091347

25. Francis DD, Diorio J, Plotsky PM, Meaney MJ. Environmental enrichment reverses the effects of maternal separation on stress reactivity. J Neurosci (2002) 22:7840-3.

26. de Kloet ER, Sibug RM, Helmerhorst FM, Schmidt MV. Stress, genes and the mechanism of programming the brain for later life. Neurosci Biobehav Rev (2005) 29:271-81. doi:10.1016/j.neubiorev.2004.10.008

27. Bredy TW, Grant RJ, Champagne DL, Meaney MJ. Maternal care influences neuronal survival in the hippocampus of the rat. Eur J Neurosci (2003) 18:2903-9. doi:10.1111/j.1460-9568.2003.02965.x

28. Cirulli F, Berry A, Bonsignore LT, Capone F, D’Andrea I, Aloe L, et al. Early life influences on emotional reactivity: evidence that social enrichment has greater effects than handling on anxiety-like behaviors, neuroendocrine responses to stress and central BDNF levels. Neurosci Biobehav Rev (2010) 34:808-20. doi:10.1016/j.neubiorev.2010.02.008

29. de Kloet ER, Joëls M, Holsboer F. Stress and the brain: from adaptation to disease. Nat Rev Neurosci (2005) 6:463-75. doi:10.1038/nrn1683

30. Handa RJ, Weiser MJ. Gonadal steroid hormones and the hypothalamopituitary-adrenal axis. Front Neuroendocrinol (2013) (in press). doi:10.1016/j. yfrne.2013.11.001

31. Joels M, Sarabdjitsingh RA, Karst H. Unraveling the time domains of corticosteroid hormone influences on brain activity: rapid, slow, and chronic modes. Pharmacol Rev (2012) 64:901-38. doi:10.1124/pr.112.005892

32. Oitzl MS, Champagne DL, van der Veen R, de Kloet ER. Brain development under stress: hypotheses of glucocorticoid actions revisited. Neurosci Biobehav $\operatorname{Rev}(2010)$ 34:853-66. doi:10.1016/j.neubiorev.2009.07.006

33. Champagne FA. Early environments, glucocorticoid receptors, and behavioral epigenetics. Behav Neurosci (2013) 127:628-36. doi:10.1037/a0034186

34. Lupien SJ, McEwen BS, Gunnar MR, Heim C. Effects of stress throughout the lifespan on the brain, behaviour and cognition. Nat Rev Neurosci (2009) 10:434-45. doi:10.1038/nrn2639

35. Kim JJ, Song EY, Kosten TA. Stress effects in the hippocampus: synaptic plasticity and memory. Stress (2006) 9:1-11. doi:10.1080/10253890600678004

36. Fenoglio KA, Brunson KL, Baram TZ. Hippocampal neuroplasticity induced by early-life stress: functional and molecular aspects. Front Neuroendocrinol (2006) 27:180-92. doi:10.1016/j.yfrne.2006.02.001

37. Champagne DL, Bagot RC, van Hasselt F, Ramakers G, Meaney MJ, de Kloet ER, et al. Maternal care and hippocampal plasticity: evidence for experiencedependent structural plasticity, altered synaptic functioning, and differential responsiveness to glucocorticoids and stress. J Neurosci (2008) 28:6037-45. doi:10.1523/JNEUROSCI.0526-08.2008

38. Bagot RC, van Hasselt FN, Champagne DL, Meaney MJ, Krugers HJ, Joels M. Maternal care determines rapid effects of stress mediators on synaptic plasticity in adult rat hippocampal dentate gyrus. Neurobiol Learn Mem (2009) 92:292-300. doi:10.1016/j.nlm.2009.03.004

39. Barha CK, Pawluski JL, Galea LA. Maternal care affects male and female offspring working memory and stress reactivity. Physiol Behav (2007) 92:939-50. doi:10.1016/j.physbeh.2007.06.022

40. Oomen CA, Soeters H, Audureau N, Vermunt L, van Hasselt FN, Manders EM, et al. Severe early life stress hampers spatial learning and neurogenesis, but improves hippocampal synaptic plasticity and emotional learning under high-stress conditions in adulthood. J Neurosci (2010) 30:6635-45. doi:10.1523/JNEUROSCI.0247-10.2010

41. Baudin A, Blot K, Verney C, Estevez L, Santamaria J, Gressens P, et al. Maternal deprivation induces deficits in temporal memory and cognitive flexibility and exaggerates synaptic plasticity in the rat medial prefrontal cortex. Neurobiol Learn Mem (2012) 98:207-14. doi:10.1016/j.nlm.2012.08.004

42. van Hasselt FN, de Visser L, Tieskens JM, Cornelisse S, Baars AM, Lavrijsen M, et al. Individual variations in maternal care early in life correlate with later life decision-making and c-fos expression in prefrontal subregions of rats. PLoS One (2012) 7:e37820. doi:10.1371/journal.pone.0037820 
43. Cao X, Huang S, Cao J, Chen T, Zhu P, Zhu R, et al. The timing of maternal separation affects morris water maze performance and long-term potentiation in male rats. Dev Psychobiol (2013) (in press). doi:10.1002/dev.21130

44. Champagne FA, Curley JP. Epigenetic mechanisms mediating the long-term effects of maternal care on development. Neurosci Biobehav Rev (2009) 33:593-600. doi:10.1016/j.neubiorev.2007.10.009

45. Claessens SE, Daskalakis NP, van der Veen R, Oitzl MS, de Kloet ER, Champagne DL. Development of individual differences in stress responsiveness: an overview of factors mediating the outcome of early life experiences. Psychopharmacology (Berl) (2011) 214:141-54. doi:10.1007/s00213-010-2118-y

46. Nederhof E, Schmidt MV. Mismatch or cumulative stress: toward an integrated hypothesis of programming effects. Physiol Behav (2012) 106:691-700. doi:10.1016/j.physbeh.2011.12.008

47. Karten YJ, Olariu A, Cameron HA. Stress in early life inhibits neurogenesis in adulthood. Trends Neurosci (2005) 28:171-2. doi:10.1016/j.tins.2005.01.009

48. Lucassen PJ, Naninck EF, van Goudoever JB, Fitzsimons C, Joels M, Korosi A. Perinatal programming of adult hippocampal structure and function; emerging roles of stress, nutrition and epigenetics. Trends Neurosci (2013) 36:621-31. doi:10.1016/j.tins.2013.08.002 [Epub ahead of print].

49. Sawada M, Sawamoto K. Mechanisms of neurogenesis in the normal and injured adult brain. Keio J Med (2013) 62:13-28. doi:10.2302/kjm.2012-0005-RE

50. Kempermann G, Jessberger S, Steiner B, Kronenberg G. Milestones of neuronal development in the adult hippocampus. Trends Neurosci (2004) 27:447-52. doi:10.1016/j.tins.2004.05.013

51. von Bohlen und Halbach O. Immunohistological markers for proliferative events, gliogenesis, and neurogenesis within the adult hippocampus. Cell Tissue Res (2011) 345:1-19. doi:10.1007/s00441-011-1196-4

52. van Praag H, Schinder AF, Christie BR, Toni N, Palmer TD, Gage FH. Functional neurogenesis in the adult hippocampus. Nature (2002) 415:1030-4. doi:10.1038/4151030a

53. Brown J, Cooper-Kuhn CM, Kempermann G, Van Praag H, Winkler J, Gage $\mathrm{FH}$, et al. Enriched environment and physical activity stimulate hippocampal but not olfactory bulb neurogenesis. Eur J Neurosci (2003) 17:2042-6. doi:10.1046/j.1460-9568.2003.02647.x

54. Joels M, Karst H, Krugers HJ, Lucassen PJ. Chronic stress: implications for neuronal morphology, function and neurogenesis. Front Neuroendocrinol (2007) 28:72-96. doi:10.1016/j.yfrne.2007.04.001

55. Czeh B, Lucassen PJ. What causes the hippocampal volume decrease in depression? Are neurogenesis, glial changes and apoptosis implicated? Eur Arch Psychiatry Clin Neurosci (2007) 257:250-60. doi:10.1007/s00406-0070728-0

56. Kempermann G, Krebs J, Fabel K. The contribution of failing adult hippocampal neurogenesis to psychiatric disorders. Curr Opin Psychiatry (2008) 21:290-5. doi:10.1097/YCO.0b013e3282fad375

57. Sahay A, Hen R. Adult hippocampal neurogenesis in depression. Nat Neurosci (2007) 10:1110-5. doi:10.1038/nn1969

58. Lucassen PJ, Fitzsimons CP, Korosi A, Joels M, Belzung C, Abrous DN. Stressing new neurons into depression? Mol Psychiatry (2013) 18:396-7. doi:10.1038/mp. 2012.39

59. Anacker C, Zunszain PA, Cattaneo A, Carvalho LA, Garabedian MJ, Thuret S, et al. Antidepressants increase human hippocampal neurogenesis by activating the glucocorticoid receptor. Mol Psychiatry (2011) 16:738-50. doi:10.1038/mp. 2011.26

60. Santarelli L, Saxe M, Gross C, Surget A, Battaglia F, Dulawa S, et al. Requirement of hippocampal neurogenesis for the behavioral effects of antidepressants. Science (2003) 301:805-9. doi:10.1126/science.1083328

61. Henn FA, Vollmayr B. Neurogenesis and depression: etiology or epiphenomenon? Biol Psychiatry (2004) 56:146-50. doi:10.1016/j.biopsych.2004.04.011

62. Lucassen PJ, Stumpel MW, Wang Q, Aronica E. Decreased numbers of progenitor cells but no response to antidepressant drugs in the hippocampus of elderly depressed patients. Neuropharmacology (2010) 58:940-9. doi:10.1016/j. neuropharm.2010.01.012

63. Lucassen PJ, Bosch OJ, Jousma E, Kromer SA, Andrew R, Seckl JR, et al. Prenatal stress reduces postnatal neurogenesis in rats selectively bred for high, but not low, anxiety: possible key role of placental 11beta-hydroxysteroid dehydrogenase type 2. Eur J Neurosci (2009) 29:97-103. doi:10.1111/j.1460-9568.2008.06543.x
64. Belnoue L, Grosjean N, Ladeveze E, Abrous DN, Koehl M. Prenatal stress inhibits hippocampal neurogenesis but spares olfactory bulb neurogenesis. PLoS One (2013) 8:e72972. doi:10.1371/journal.pone.0072972

65. Koehl M, Lemaire V, Mayo W, Abrous DN, Maccari S, Piazza PV, et al Individual vulnerability to substance abuse and affective disorders: role of early environmental influences. Neurotox Res (2002) 4:281-96. doi:10.1080/ 1029842021000010866

66. Mandyam CD, Crawford EF, Eisch AJ, Rivier CL, Richardson HN. Stress experienced in utero reduces sexual dichotomies in neurogenesis, microenvironment, and cell death in the adult rat hippocampus. Dev Neurobiol (2008) 68:575-89. doi:10.1002/dneu.20600

67. Rayen I, van den Hove DL, Prickaerts J, Steinbusch HW, Pawluski JL. Fluoxetine during development reverses the effects of prenatal stress on depressivelike behavior and hippocampal neurogenesis in adolescence. PLoS One (2011) 6:e24003. doi:10.1371/journal.pone.0024003

68. Madhyastha S, Sekhar S, Rao G. Resveratrol improves postnatal hippocampal neurogenesis and brain derived neurotrophic factor in prenatally stressed rats. Int J Dev Neurosci (2013) 31:580-5. doi:10.1016/j.ijdevneu.2013.06.010

69. Wang H, Gondre-Lewis MC. Prenatal nicotine and maternal deprivation stress de-regulate the development of CA1, CA3, and dentate gyrus neurons in hippocampus of infant rats. PLoS One (2013) 8:e65517. doi:10.1371/journal. pone. 0065517

70. Oomen CA, Girardi CE, Cahyadi R, Verbeek EC, Krugers H, Joëls M, et al. Opposite effects of early maternal deprivation on neurogenesis in male versus female rats. PLoS One (2009) 4:e3675. doi:10.1371/journal.pone.0003675

71. Oomen CA, Soeters H, Audureau N, Vermunt L, van Hasselt FN, Manders EM, et al. Early maternal deprivation affects dentate gyrus structure and emotional learning in adult female rats. Psychopharmacology (Berl) (2011) 214:249-60. doi:10.1007/s00213-010-1922-8

72. Mirescu C, Peters JD, Gould E. Early life experience alters response of adult neurogenesis to stress. Nat Neurosci (2004) 7:841-6. doi:10.1038/nn1290

73. Kumar G, Jones NC, Morris MJ, Rees S, O’Brien TJ, Salzberg MR. Early life stress enhancement of limbic epileptogenesis in adult rats: mechanistic insights. PLoS One (2011) 6:e24033. doi:10.1371/journal.pone.0024033

74. Hulshof HJ, Novati A, Sgoifo A, Luiten PG, den Boer JA, Meerlo P. Maternal separation decreases adult hippocampal cell proliferation and impairs cognitive performance but has little effect on stress sensitivity and anxiety in adult Wistar rats. Behav Brain Res (2011) 216:552-60. doi:10.1016/j.bbr.2010.08.038

75. Suri D, Veenit V, Sarkar A, Thiagarajan D, Kumar A, Nestler EJ, et al. Early stress evokes age-dependent biphasic changes in hippocampal neurogenesis, BDNF expression, and cognition. Biol Psychiatry (2013) 73:658-66. doi:10.1016/ j.biopsych.2012.10.023

76. Buwalda B, Stubbendorff C, Zickert N, Koolhaas JM. Adolescent social stress does not necessarily lead to a compromised adaptive capacity during adulthood: a study on the consequences of social stress in rats. Neuroscience (2013) 249:258-70. doi:10.1016/j.neuroscience.2012.12.050

77. Hu P, Oomen C, van Dam AM, Wester J, Zhou JN, Joels M, et al. A singleday treatment with mifepristone is sufficient to normalize chronic glucocorticoid induced suppression of hippocampal cell proliferation. PLoS One (2012) 7:e46224. doi:10.1371/journal.pone.0046224

78. McClelland S, Korosi A, Cope J, Ivy A, Baram TZ. Emerging roles of epigenetic mechanisms in the enduring effects of early-life stress and experience on learning and memory. Neurobiol Learn Mem (2011) 96:79-88. doi:10.1016/j.nlm.2011.02.008

79. Koo JW, Russo SJ, Ferguson D, Nestler EJ, Duman RS. Nuclear factorkappaB is a critical mediator of stress-impaired neurogenesis and depressive behavior. Proc Natl Acad Sci U S A (2010) 107:2669-74. doi:10.1073/pnas. 0910658107

80. Anacker C, Cattaneo A, Musaelyan K, Zunszain PA, Horowitz M, Molteni R, et al. Role for the kinase SGK1 in stress, depression, and glucocorticoid effects on hippocampal neurogenesis. Proc Natl Acad Sci U S A (2013) 110:8708-13. doi:10.1073/pnas.1300886110

81. Bagot RC, Tse YC, Nguyen HB, Wong AS, Meaney MJ, Wong TP. Maternal care influences hippocampal N-methyl-D-aspartate receptor function and dynamic regulation by corticosterone in adulthood. Biol Psychiatry (2012) 72:491-8. doi:10.1016/j.biopsych.2012.03.016 
82. Weaver IC, Cervoni N, Champagne FA, D'Alessio AC, Sharma S, Seckl JR, et al. Epigenetic programming by maternal behavior. Nat Neurosci (2004) 7:847-54. doi: $10.1038 / \mathrm{nn} 1276$

83. Weaver IC. Epigenetic effects of glucocorticoids. Semin Fetal Neonatal Med (2009) 14:143-50. doi:10.1016/j.siny.2008.12.002

84. Jacobson-Pick S, Richter-Levin G. Differential impact of juvenile stress and corticosterone in juvenility and in adulthood, in male and female rats. Behav Brain Res (2010) 214:268-76. doi:10.1016/j.bbr.2010.05.036

85. Spalding KL, Bergmann O, Alkass K, Bernard S, Salehpour M, Huttner HB, et al. Dynamics of hippocampal neurogenesis in adult humans. Cell (2013) 153:1219-27. doi:10.1016/j.cell.2013.05.002

86. Knoth R, Singec I, Ditter M, Pantazis G, Capetian P, Meyer RP, et al. Murine features of neurogenesis in the human hippocampus across the lifespan from 0 to 100 years. PLoS One (2010) 5:e8809. doi:10.1371/journal.pone.0008809

87. Boldrini M, Hen R, Underwood MD, Rosoklija GB, Dwork AJ, Mann JJ, et al. Hippocampal angiogenesis and progenitor cell proliferation are increased with antidepressant use in major depression. Biol Psychiatry (2012) 72:562-71. doi:10.1016/j.biopsych.2012.04.024
Conflict of Interest Statement: The authors declare that the research was conducted in the absence of any commercial or financial relationships that could be construed as a potential conflict of interest.

Received: 25 December 2013; paper pending published: 14 January 2014; accepted: 31 January 2014; published online: 20 February 2014.

Citation: Loi M, Koricka S, Lucassen PJ and Joëls M (2014) Age- and sex-dependent effects of early life stress on hippocampal neurogenesis. Front. Endocrinol. 5:13. doi: 10.3389/fendo.2014.00013

This article was submitted to Neuroendocrine Science, a section of the journal Frontiers in Endocrinology.

Copyright (c) 2014 Loi, Koricka, Lucassen and Joëls. This is an open-access article distributed under the terms of the Creative Commons Attribution License (CC BY). The use, distribution or reproduction in other forums is permitted, provided the original author(s) or licensor are credited and that the original publication in this journal is cited, in accordance with accepted academic practice. No use, distribution or reproduction is permitted which does not comply with these terms. 